Libertas Mathematica (new series)

Volume 33(2013), No. 1, 135-148

\title{
Francesco S. De Blasi remembered by close friends and colleagues
}

\section{Francesco Saverio De Blasi}

Francesco was born in Naples in 1941, but his home town was Amorosi in "Sannio", a small region in the south of Italy. His family belonged to the upper class, his father was a physician, also his uncles on his father's side were professional physicians and one of them was a famous surgeon and worked in the United States. Francesco attended the gymnasium in Cerreto Sannita a small centre next to the roman town of Telesia and the high school in the Lyceum "Luigi Sodo", an important school in the southern Italy, run by Franciscans, but not of religious orientation.

Being a family of physicians, they hoped that also Francesco would undertake the same career and possibly follow his uncle in the US. But Francesco had different ideas as he was very much attracted by classical studies and philosophy. He ended the Lyceum with the maximum score and, with big disappointment of his family, he enrolled at Mathematics in the University of Naples where he graduated with laude in the year 1964. He was assistant in the University of Naples in the period 1964-66. Then from 1966 to 1967 he was a lecturer in the University College of London. Hence from 1968 to 1969 he taught in Salisbury, Rhodesia. Then, with a Nato fellowship, he was in Warwick in the period 1970-71.

Roberto Conti who was professor in the University of Florence and director of the group of Mathematical Analysis at National Research Council noted Francesco's value and offered him a position in the University of Florence and here he was assistant professor from 1971 to 1976 and full professor from 1976 to 1981. Then he moved to the University of Roma 2 "Tor Vergata" and there he was full professor from 1981 until his retirement in the year 2012.

For his human qualities and for his kindness Francesco was appreciated by all his colleagues. I, who had the privilege to frequent him in his private sphere, could seize his humanity and his extraordinary sense of modesty which appeared increased, due to his wealthy social and economical condition. Also his clothing was modest. Seldom he wore a jacket and for many years I saw him with the same grey overcoat and never a tie! As I have said before Francesco spent the initial period of his carrier 
in Florence and here he often used to return and here we wrote all our papers.

The scientific interests of Francesco were, at the beginning, about the theory of fixed points, then in the 70's about generic properties. From 1980 onwards his interests turned to the differential inclusions and during this long period he and me worked together.

Francesco was a very shy man but this shyness disappeared in mathematical environment. At meetings he felt at ease, in a good mood and witty. As he disliked the use of a computer, even if all the lecturers made use of it, he used a blackboard, nevertheless his lectures were well prepared and very clear.

He never overestimated himself and he had a deep admiration towards those colleagues who did good mathematics without boasting; on the contrary he was very severe towards those groups whose major dowry was that of self promoting.

Francesco was a great worker and this quality increased in the last period of his life. Even if his trips to Florence were less and less frequent, he did not decrease his scientific care.

I remember that he used to call me almost every day to tell me that we had to work on that or the other problem which had been left unfinished.

Just a week before his death we were discussing mathematics in his apartment in Rome. But he knew that his life had come to an end.

We continue to love each other and I continue to love him very much.

Here is the last picture of him that I have

Giulio Pianigiani, University of Florence, Italy

\section{Francesco Saverio DE BLASI}

Francesco Saverio De Blasi, Professor of Mathematical Analysis, died in Rome on March 21, 2012.

Francesco was a scientist of superb quality, as evidenced by his over 150 publications in the field of mathematical analysis and in particular of multifunctions.

He graduated from the gymnasium in Naples and also studied at the University in that city.

He was firmly opposed to military service, and this fact led to a rather trying time in civilian service in Rhodesia (the region now known as Zimbabwe).

Back in Italy he accepted an appointment as a professor at the University of Florence in the beginning of the '70s: he spent about ten years there, always in continuous, friendly, cheerful interaction with his young mathematical colleagues."

"He is remembered by everyone as a beautiful human being"

I had the privilege to know him and be with him when, as a professor of mathematics for Architecture students, he had to endure many threats - even to his person 


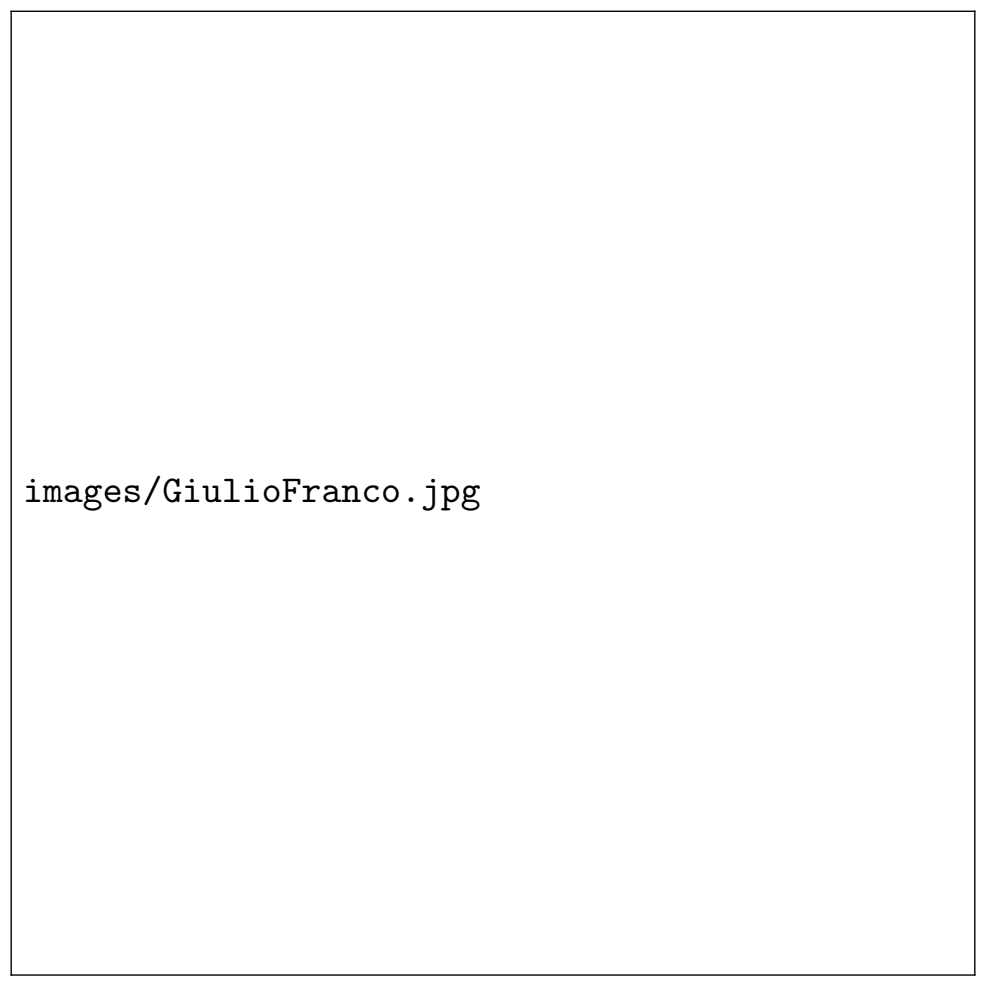

and to his home - as a consequence of the student protests of the late 70 s. Francesco displayed, then and on many other occasions, the intransigence of meek people, the moral sense that pervaded him, which was however combined with extreme personal kindness.

After his death I had the occasion to talk with some friends of Francesco: I would like to recall here what one of them said to me.

- "During the very hard years of the student protests I was appointed chairman of an examination committee for a student who was imprisoned.

According to the rules, the student should have been transferred to Florence, where the exam would have taken place.

For safety reasons, his family asked me to arrange things in such a way as to hold the examination in the maximum security prison where the student was being held. In order to form a committee of examiners, it was necessary to have the collaboration of two other professors. Francesco immediately agreed to participate in this particularly intense experience".

This was Francesco de Blasi: the absolute respect which he displayed towards his colleagues, his students, his friends, and the institutions he served were charac- 
teristics that rarely, in my memory, are to be found in the academic world.

On behalf of his many friends, I give a very big departing hug to Francesco.

- Giuseppe Anichini, University of Florence, Italy

\section{Francesco}

I met Francesco De Blasi in Florence, in the early seventies.

At that time a reasonably large number of young mathematicians, mainly interested in ordinary differential equations, were active at the Istituto Ulisse Dini, one of the very few institutions in Italy where ordinary differential equations, to the opposite of partial differential equations, then prevailing in most Italian universities, were alive as a research topic.

The Istituto Ulisse Dini had, in general, several visitors from abroad, rather regular seminars and it was a point of attraction for young researchers.

Differential inclusions (possibly at that time they were called differently) was one of the topics, and I shared this interest with Francesco.

Besides seeing each other on institutional (mathematical) occasions, from time to time we met also on social occasions; one of the happiest memories I have of that time it was the fact that we were friends among (young) colleagues, and used to met socially; it is something I have not seen in other Departments where later I moved; possibly it was simply a question of age.

In the later seventies I moved to Padova, and I saw Francesco rather irregularly.

Although we shared common interest, we have no paper in common, and I followed his work at a distance, mainly through discussions with our common friend Giulio Pianigiani, with whom, at that time, he was developing the Baire Category approach.

Francesco has been a very remarkable and unusual human being, very original in his ways of addressing life and mathematics.

What stroke you about him was his kindness and his refusal of anything aggressive. However, this was only the outside. Inside, he was a person of a strong moral character, that knew without hesitation what was right and what was wrong, a person that would live according to his principles and would be ready, if needed, to pay a price for it. Francesco would not even think of compromising on matters of principle.

He would never try to impose on others his opinions but simply, calmly, he would state what he would do.

I have been proud to be a friend of his and I regret not having spent more time with him and profited more of his views and opinions. 


\section{My memories of Francesco}

I cannot exactly say when I met Francesco for the first time. But, it surely was just a little after 1979, when I graduated, and at some meeting where Arrigo Cellina was involved. Actually, on the occasion of my "laurea" thesis, I begun to approach setvalued analysis, contacting Arrigo who morally headed the italian group of scholars in that field to whom Francesco did belong.

Since then, I met Francesco at several conferences and, each time, I did enjoy to discuss with him about mathematical themes of common interest.

But, unquestionably, my strongest memory is related to the ICNODEA 2001 held in Cluj-Napoca from 12 to 15 September 2001, so just after the attack to the twin towers. Actually, we were together Francesco, his wife, my son (at that time 13 years old) and me. I well remember the discussions between we four on a broad range of topics, and, in particular, the alive interaction between Francesco and my son.

In conclusion, I always will remember Francesco as a fine mathematician, of great technical ability, and as an even finer man of full substance and no vacuous appearance.

Biagio Ricceri, University of Catania, Italy

\section{Francesco, friend and colleague}

Francesco's death distressed the senior and the younger faculty members, as well as the students of the Tor Vergata University - he had been one of the founding members there.

The whole Department, though, including those who only knew him after the beginning of his illness, will miss him. Until the end, everybody knew that he was seriously ill, but nobody understood how advanced his illness was.

Francesco was always rational, earnest and rigorous in his approach about the whole world, but was deeply kind, friendly and sensitive on the human side. He ignored any power-seeking approach, he shared with his wife Helene and his friends a private world of affection and shared cultural experience.

His passion for classical culture, the ancient Greek civilization in particular, enriched his rational vision of the world: he avoided the irrational short-cuts that some people choose in order to understand the negative features of the world we live in. His ethic vision was turned into political engagement: in our university he was an active promoter and supporter of a committee against war, established after 1999 and particularly active during the war in Iraq.

Generally speaking, he fought against any attitude that would even faintly toler- 
ate injustice, because he held the principles and had the ability to see the right and wrong side in any conflict. He was uncompromising from the ethical point of view, nevertheless his opinion was always requested because he was a very skilful solver of specific problems and conflicts.

Francesco was always ready to help, in his private and reserved way: many are the people who were supported and encouraged by him. He did not like to appear and kept a low profile about his outstanding human and intellectual qualities, but certainly was an "hombre vertical" as the Spanish people say.

He will be remembered not only as a valued mathematician, but also as a kind, rational, great human being. His departure makes all of us feel lonely.

- Lucio Damascelli, University of Roma "Tor Vergata"

\section{Francesco, friend and collaborator}

Professors G. Pianigiani and L. Damascelli spoke about F. S. De Blasi with great aptitude as far as regards his scientific and human profile. For my part, on insistence of prof. V. Staicu, I shall add - with great hesitation - some personal reminiscences and of my long acquaintance with Francesco as was familiarly called. My hesitation is due to my sense of impossibility to describe the richness of such a personality as that of Francesco.

I met Francesco in 1975, and since then our collaboration developed in a friendship that continued till the end of his life. My scientific career was strictly connected with that of his. Our collaboration had as results 47 published works but our discussions on mathematical topics were of a much larger scope. It is that acquaintance which decided for my professional and private life, that is to start working and living in Italy. Francesco was always a strong point of moral support in my changing altogether life and country.

It is difficult to qualify with common adjectives his rich and polyhedral personality. If I can say whit my poor words something about his character, I should start attesting his capacity of objective reasoning orientated towards a pragmatic reality, but on the other hand he aspirated after perfection both aspects being reflections on his philosophical formation. He wholeheartedly was for justice especially in faculty decisions. His intransigence in defending his opinions originated in his interest to improve the issue in discussion but he was ready to change opinion if he were convinced of the justice of different proposals.

Sense of independence and freedom of thinking were manifested very early in his life. He followed the studies of his choice in spite the family pressure to study medicine. He was indifferent of scholar distinctions in his school years considering them an injustice with respect of those less able school mates. 
He closely followed political and social ideas and was critical in decisions which were not conform with his primal interests concerning in the welfare of the less advantaged. His political sympathies were in accordance with his principles, for this reason is why he was the severest critic of his own political adherences.

What mostly was impressing in him was his extensive culture. His interest in ancient Greece civilization was part of his lectures. Among his vast readings special position held the ancient Greek philosophy and the archaic Greek poets. Philosophy in general was his primary hobby. His preferences was towards Logical Analysis. His intellectual curiosity included interest in visual arts and music combined with his philosophical interest. Characteristic is in this respect his emotional preference for Raffaello's School of Athens.

In private life he shared with his wife the interest in philosophical ideas. They were frequently involved in infinite discussions especially on Greek thinkers, a subject of his prediction. That point makes his absence quite intolerable for his wife.

He loved nature in all its manifestations. His Pythagorean respect of living things was exceptional. I remember that once, being is his place in Florence, armed with our last paper I tried to kill a mosquito that was wandering about. Francesco, on noticing my intension, took me apart and told me in a sever tone: I put you out and our collaboration is finished if you dare to make an attempt on the life of a mosquito in my house.

He was tormented by claustrophobia which prevented him to travel in airplane even in train, but with a tremendous amount of determination and with force that he succeeded to overcome in a considerable level this handicap, so that finally his favorite way of traveling was that by airplane, while his first travel to the States, in the early seventies, was by the transatlantic Michelangelo.

His strong personality manifested early in his life. His school-fellow Mr. Mario Parisi in his reminiscences speaks about that. He records that in Valle Telesina, a part of the Beneventano, two families in the forties were important, that is his parents families. They possessed conspicuous immobile property in the area and were professionals. In his father family, dwelling in Faicchio, the profession of medical doctor was that of his father and his uncle, while in his maternal family in Amorosi, the grand father was pharmacist and an uncle was eminent doctors in Naples. The rest of the family consisted in two uncles and one aunt all pharmacists.

Francesco spent his early years in Amorosi where he finished his primary education. Summer vacations usually he spent in Faicchio where it was also his father's clinic, which was not only a clinic but a center of hospitality for many patients and friends.

He finished the secondary education in Ceretto Sanita, a school run by priests, one of the best in the area. The majority of students there came from country 
families, some came from merchants or public functionaries. Francesco was the only one comings from a professional family. His extraordinary intelligence was never ostentatious. His character was rather reserved and inclined to modesty. His excellence in studies not influenced his independent thinking. He was against any premium because as he was saying a premium to the better students discouraged the weaker ones. He appeared always humbly dressed, to the despair of his mother who in vain bought for him elegant clothes which he regularly refused to wear. This humble appearance was one of his characteristics the whole of his life. He never were a necktie and in special occasions he could rarely a dark suite.

He resisted strong family pressure to study medicine. His inclination towards sciences brought him to study physics and mathematics. At the university of Naples where he studied, he joined the team of the famous mathematician Carlo Miranda before graduated. The participants of this team where destined for a scientific career in the same university. The strict circle of that group and the feudal atmosphere that prevailed there cause in him a feeling of asphyxia of which he liberated by escaping away. He was directed first in Strasbourg where there was a mathematical school interested in topics congruous with his own interests. Soon he was offered teaching duties there for a whole academic year. He was compelled to leave Strasbourg because of military service in Italy. Because of his strong pacifistic feelings he hated all military matters and tried some equivalent occupations instead of military service. For this reasons he found a teaching position at the University of Rhodesia in South Africa (now Zimbabwe). He spend an academic year in this position.

His scientific interests pressed him to join research centers. He found the opportunity to start postgraduate studies in the States at Brown University entering in the circle of professor La Salle. Unfortunately he was not satisfied with the assigned supervisor and for that reason he abandoned this place.

Returned to Europe he found more suitable to start free research at University of the Warwick in England with a special grant. On the suggestion of professor M. Cartwright of Cambridge University, a specialist in the field which Francesco was interested, he entered the group of professor R. Conti of Florence University, which was an international mathematical center.

There he got the opportunity to meet professor A. Lasota, whit whom collaborated in three papers. Because of scientific correspondence between University of Cracow (where I was working) and the Florence School of Differential Equations, I found my self in Florence in 1975 in the group of professor Conti. Francesco noted me as being a former student of Lasota and proposed me a collaboration. This was the start a fruitful cooperation over long duration is ended in the publication of several papers.

Because of this strict contact with him I have been able to consider his extraor- 
dinary courage as witnessed at the time of "anni di piombo", a time of political disorder present in many sectors of public life and in especially in University environment. Various faculties, among them the Faculty of Architecture in Florence where Francesco was teaching, were occupied by "revolutionary students". They requested to replace mathematics exams with a discussion on "social thinking". Some of the teaching staff yielded. Francesco resisted the enormous and violent pressure which amounted in his unlawful detention and threats for his life. The atmosphere of violence was accentuated by attempts upon houses of lectures with incendiary bomb (Molotov) among which was the house of Francesco in primis.

In my personal reminisces strong remains in my memory the scene of "a revolutionary assault" on the Mathematics Department Ulisse Dini at Florence. In a room there where professor Conti, Francesco and I when some persons entered the head covered with hoods and with a very fearful aspect. Conti and I were paralyzed with fear. Francesco had disappeared. Soon it was known that those invaders were looking for two persons, professor G. Goodman, an American subject, and Francesco. Fortunately Goodman was absent and Francesco out of sight. Later Francesco spoke to me about his hiding place in the basement where a part of the library was situated. With an extraordinary presence of spirit he had immediately intermingled with the assaulters and made his way out from the room at the same moment of their entering.

After some time when things got better the minister of education in order to express appreciation invited Francesco along with other members of the scientific staff of the Faculty of Architecture who had resisted "revolutionary" pressures. The train that brought the staff in Rome arrive there with considerable delay. Francesco's colleagues hurried to take a taxi. All except Francesco who in his desire to denounce the bad functioning of public transportation decided to take a public bus. He arrived at the same moment when the minister was also appearing, that is with a considerable delay. Francesco was disappointed because he could not denounce the bad functioning of public transportation as it had been his intention to do.

In difficult situations Francesco's presence of spirit supplied him with successful resolutions. Once in Poland where we were driving in the country a torrential rain caused extensive floods. Our vehicle was found on a high place surrounded by water. While I was helplessly looking at the heightening water Francesco found the way out. It was late in the night and very dark. Francesco was keen in observing the surroundings and was able to notice some path leading to a nearby church in a higher place. We took some cemetery slabs from the nearby churchyard which we put on the path and in this way we were able to move the car near the church. We spent all night in a considerably safe place in the car while the surrounding meadows were flooded. Next day when the water was lower we were able to continue our travel to 
the Equadiff meeting at Prague.

Once he was driving to Barcelona for a meeting. On the starting day of the congress Francesco was near the city, but he had lost his way. Arrived finally at the place of the meeting he found that he was, according to the program, the first speaker and he had missed his talk. Indignant with himself for the delay he took immediately the way of return. Some mathematicians who have noticed his short presence were not trusted when reported that they had seen him in the premises.

His attachment to his teaching duties was exceptional. He never missed a lesson in all his teaching career. He expected the same from his colleagues. He had never taken a sabbatical year in his forty years of service because of his conviction that these leaves were contrary to his teaching duties and even qualified them as parasitical. He refused financial support when he followed scientific conferences if he had not contributed.

His attitude toward electronics at a time of expansion of their use, as means of writing and communication, was negative. He continued to compose his works in hand-writing. His method was to write and rewrite the whole work supplied with pencil and rubber. His homogeneous elegant small writing was a point of admiration for his collaborators. The manuscripts of a single work increased in number this way, but at least when reached the final draft was of his complete satisfaction.

Our strict collaboration in the first years compelled me to makes frequent visits to Italy. Those days traveling from East of Europe to the West was difficult especially for financial disequilibrium, but my visits continued regularly because as I later realized Francesco largely contributed by his own means. As far as I know this kind of financial assistance from Francesco was extended to many mathematicians of the Eastern Europe. I must say that especially in the early years of our collaboration the scientific contribution of Francesco was for me of primary importance because his fertile mind provided me with a variety of proposals.

Every work undertaken by us was a fascinating intellectual adventure. It was extremely delightful to discuss mathematics with Francesco because his love for his subject transported him, and I believe whoever was with him, almost in ethereal places.

Since our first contacts it became clear that it was also entertaining working together. My first work with him went like this. We were working to resolve a certain problem. After some unsuccessful attends one morning I tried independently a new way by making certain calculations but according my opinion without making any progress. Francesco intervened and affirmed that with my approach to the problem had already reached solution. I was not completely convinced but he with decision prohibited any interruption till complete demonstration. We had no lunch, no break, no dinner. Finally, only very late in the night when proof was complete 
we had excellent spaghetti in his place prepared by him in his favorite "napolitan" way. This was my first visit to Francesco's house (at 3 a.m). It was not possible to be introduced to his wife because she was in bed. Afterwards I was a regular guests of Francesco's household .

Some time each of us proposed a different problem. The one Francesco proposed was, according my opinion, of less importance as also more difficult to elaborate. He took in consideration my problem but under the condition to work also on his problem. Both papers appeared, that proposed by Francesco is the most cited one till today of all our common papers, that one proposed by me totally disappeared.

When I started work in L'Aquila we met in Rome once a week. After a day of intense work and discussion we used to go to a pizzeria at the popular quarter of San Lorenzo for a pizza and wine of the house. After having eaten and drunk to satisfaction Francesco used the paper tablecloth to jot down proofs and calculus. It happened that the solutions of a problem discussed the whole day was completed in those moment. We used to go away with me having saved the precious tablecloth. This notes often fished in published papers. It was not only in pizzerias that we working outside our studios. Like real Peripatetics will could discuss mathematics in the open air as for instance on the picturesque Tuscan hills or the refreshing Abruzzo woodlands.

Missing Francesco for me meant the forever loss of the fascinating experience of working together, as also the exchange of ideas in various intellectual topics, something that I believe makes his absence heavily felt by his familiars and friends. - Józef Myjak, Faculty of Applied Mathematics A.G.H, Kraków, Poland

\section{Francesco, a good friend}

I met Francesco for the first time in the Library of the Mathematical Institute "Ulisse Dini", in August 1986. We had a short conversation from which I understood that he knew many mathematicians in Romania. In particular, he asked me about Stefan Mirica, my former supervisor at University of Bucharest, whom he had met at Warwick University in the early 70s.

I was impressed by his kindness and modesty. With simple words he encouraged me and offered me his advice and support.

Later I discovered the richness of Francesco's personality and his extensive culture. His extraordinary intelligence and fine judgement were never ostentatious. He was always rational, earnest and rigorous, with strong principles and strong convictions, that he followed but never tried to impose. Francesco displayed respect for everybody, colleagues or students.

We met several times during my stay in Florence; once he introduced me to his 


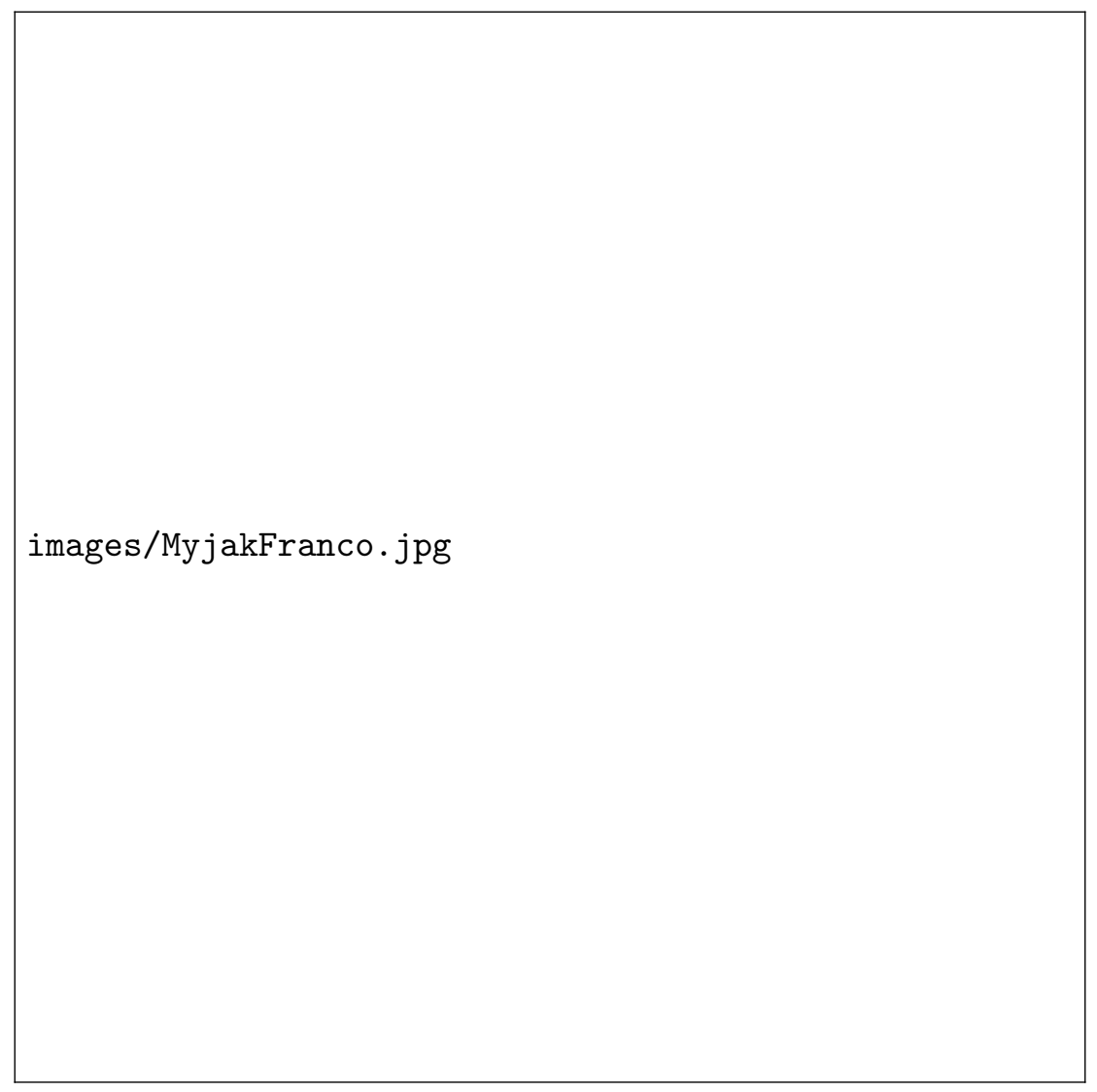

friend and collaborator, Josef Myjak, also originated in Eastern Europe, who was passing in Florence, coming from Trieste.

We discussed the scientific environment from SISSA and I was so impressed that I decided to apply there for a $\mathrm{Ph}$. D. Fellowship. That was of extreme importance for me and greatly changed my life. This is just one example of how Francesco understood to guide and help young people coming from Eastern Europe.

During my stay at SISSA, I visited Francesco several times at the University of Rome "Tor Vergata", and I had the opportunity to discover the fine mathematician and exceptional teacher, the generous, modest and always available man, that Francesco was until the end of his life.

After many hours of intensive work and extremely delightful mathematical discussions, that recharged my batteries for a few weeks, we used to go to a pizzeria at the popular quarter of San Lorenzo, where we continued our reasoning, stimulated by a glass of wine and a pizza Napoletana. 
Since Trieste is not so close to Rome, every one of my trips to Rome was at least for two days, and for the night I always booked Hotel Archimede, suggested by Francesco. So, we always had dinner together, in a good restaurant but using paper tablecloth to avoid unnecessary costs, which is also useful to note any idea or doubts on discussions that we had during the day. Francesco never refused a good pizza or a plate of spaghetti, even if he entered the restaurant with vegetarian beliefs.

After my departure to Portugal, we met several times in Florence, where together with our common friend Giulio Pianigiani we wrote two papers. But our phone calls were frequent and our friendship continued. In 2006 Francesco visited Aveiro and participated in the conference Views on ODEs in honor of Arrigo Cellina and James Yorke, and he promised me to come back soon, also to complete some research papers in progress, but this was not possible unfortunately.

I was always aware of his health problems but I didn't suspect how serious the disease was and how soon he would leave us.

Two years ago, I met Francesco at Loughborough University, UK, where the international conference on Differential Equations "Equadiff 2011" was organized. I tried to spend as much time as possible with him and his wife.

Shortly after accepting the invitation of Professor Constantin Corduneanu to prepare a new mathematical journal in order to re-launch Libertas Mathematica, whenever I had more questions than answers and felt an acute need to share with someone doubts and seek solutions, I was happy to meet Francesco.

We talked a lot at Loughborough, and continued to exchange emails and talk on the phone. Later I learned that he answered my calls from his hospital bed.

His concern for finishing the scientific work he had started and for the scientific quality of this work did not decrease until the last minute.

I was lucky to meet Francesco and I feel quite honored that we were good friends. Naturally, I sincerely regret not spending more time together, doing math or simply absorbing his great culture and particular view of life.

This is the last picture of him that I have, made during the conference dinner at Loughborough, in August 2011.

- Vasile Staicu, University of Aveiro, Portugal 
images/EquadiffFranco.jpg 